\section{Eye injury as a result of coat toggle trauma}

elasticated cord recoiled and struck him in the right eye. On initial examination, the patient had a visual acuity of hand movements and a traumatic hyphaema of $1 \mathrm{~mm}$ depth with a poor fundal view. The intraocular pressure was $14 \mathrm{mmHg}$. The hyphaema cleared over the next few weeks and revealed an underlying anterior subcapsular lens opacity (Figure 2 ). His visual acuity by this stage had improved to 6/18 (20/60) unaided, 6/5

$(20 / 15)$ with a pinhole. Gonioscopy and fundal exam were normal. The patient declined cataract surgery and is under review.

\section{Case 2}

A 67-year-old gentleman similarly suffered injury to his right eye when trying to free his coat toggle from the seatbelt mechanism in the back seat of a car. Upon prompt presentation to the eye department, his visual acuity was hand movements with good projection and he had a corneal abrasion with a $1.2 \mathrm{~mm}$ hyphaema. The patient was managed in the first instance with topical steroids, antibiotics and a cycloplegic. Upon review, a week later a traumatic cataract had developed and 2 clock hours of iridodialysis could be easily identified (Figure 3). Further slit lamp examination revealed the presence of vitreous within the anterior chamber associated with the area of dialysis. A B-scan ultrasound revealed an intragel haemorrhage without any evidence of a retinal detachment. The gentleman underwent a right pars plana vitrectomy with fragmatome lensectomy. Postoperative visual acuity continues to improve and most recently was up to $6 / 9(20 / 30)$ with pinhole correction.

Case 3

Accepted in revised form: 4 August 2005 Published online: 25

November 2005

The authors have no proprietary interest or research funding

\section{Introduction}

recent years there has been a vogue towar other outer garments. Often a metal or hard plastic toggle is used to maintain the tension in such clothing (Figure 1). We describe three cases where there has been direct eye trauma as a result of high-velocity elastic 'recoil' of these devices towards the globe. To our knowledge, the medical literature. We wish to alert the ophthalmic community to the potential perils of such elasticated toggles.

\section{Case 1}

A 61-year-old gentleman was attempting to remove his jacket from the back seat of his car when it became entangled in the seat belt mechanism. In an attempt to free the coat, he gave it a sharp pull and, as a result, its
A 45-year-old lady sustained significant blunt trauma to her left eye as a result of being struck with an elasticated toggle from her coat. On initial examination, a small corneal abrasion, $2 \mathrm{~mm}$ hyphaema and traumatic mydriasis were 


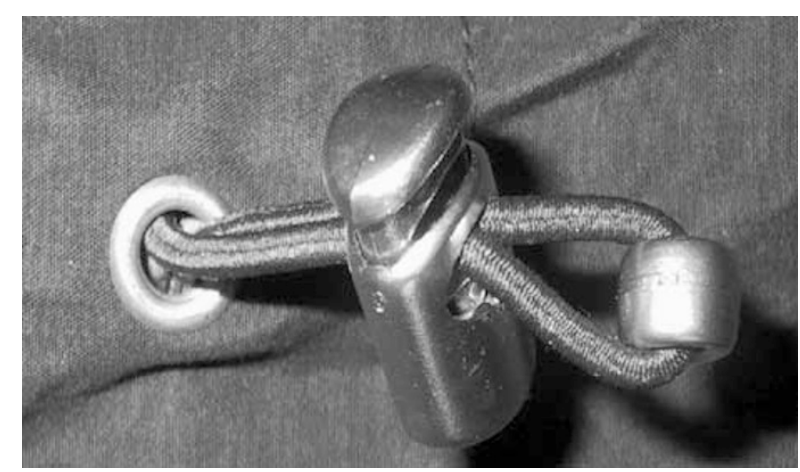

Figure 1 Coat toggle.

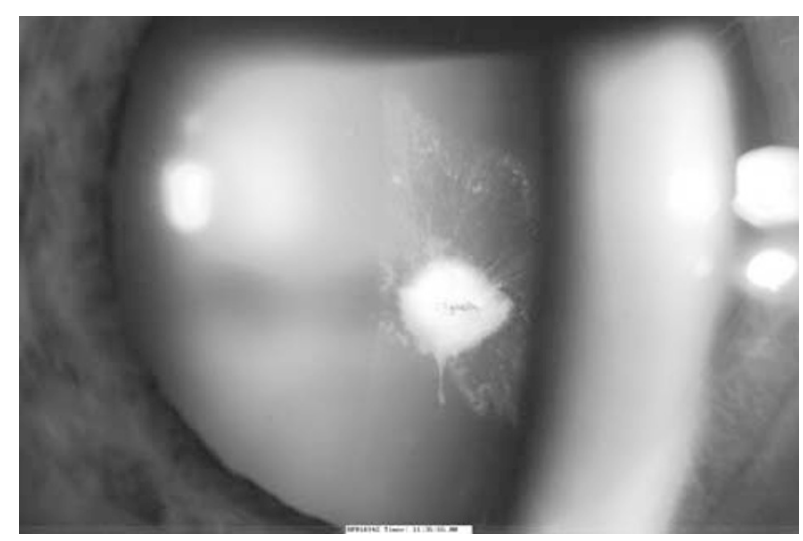

Figure 2 Anterior sub-capsular cataract.

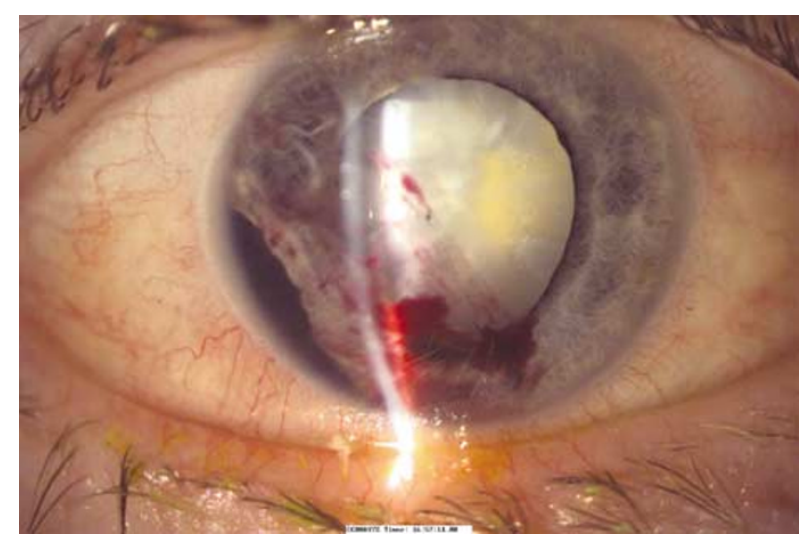

Figure 3 Inferior angle recession and hyphaema. noted. She was started on topical steroids and mydriatics and $48 \mathrm{~h}$ later her intraocular pressure measured as $40 \mathrm{mmHg}$ and oral acetazolamide was started. The pressure responded promptly, however, once the hyphaema cleared an anterior subcapsular cataract and 4 clock hours of inferior angle recession of the anterior chamber were noted. The patient was kept under close scrutiny, and 1 month after the initial injury, careful examination revealed the presence of an inferior retinal tear in the left eye. This was treated with argon laser retinopexy. The patient underwent cataract extraction 18 months after presentation. During the surgical procedure, a capsular tension ring was required due to an inferior zonular dialysis. Postoperative visual acuity of $6 / 6(20 / 20)$ was obtained with appropriate correction.

\section{Discussion}

This report presents three eyes of three patients with sight threatening ocular injuries as a direct result of blunt trauma with elastic drawstrings. The cases illustrate the spectrum of sequelae associated with such injuries, ranging from moderate cataract to retinal tears and angle recession. The mechanism of injury in these individuals was that of blunt trauma and is reminiscent of the consequences of bungee-cord trauma previously described in the literature. ${ }^{1,2,3}$

With the more widespread use of these 'performance type' outer garments, these types of injuries may become more common. We recommend a change in design to either incorporate 'soft' toggles or employ a nonelasticated drawstring.

\section{References}

1 Chorich LJ, Davidorf GH, Chambers RB, Weber PA. Bungee cord - associated ocular injuries. Am J Opthalmol 1998; 123: 270-272.

2 Aldave AJ, Gertner GS, Davis GH, Regillo CD, Jeffers JB. Bungee Cord-associated trauma. Ophthalmology 2001; 108: 788-792.

3 Brouzas D, Charakidas A, Papagiannakopoulos D, Koukoulomatis P. Elastic cord-induced ocular injuries. Injury Int J Care Injured 2003; 43: 323-326. 